\title{
Risk-based construction safety index as an integral indicator in the agricultural sector
}

\author{
Tatiana Simankina ${ }^{1}$, Marina Romanovich ${ }^{1, *}$, Vladimir Sharmanov ${ }^{2}$, Anton $_{\text {Mamaev }}^{2}$ and \\ Angelina Blagodatskaya ${ }^{3}$ \\ ${ }^{1}$ Peter the Great St. Petersburg Polytechnic University, 29, Polytechnicheskaya str., 195251, Saint \\ Petersburg, Russia \\ ${ }^{2}$ LLC "Scientific - Technical Center" Etalon ", 2, Bogatyrsky Prospekt, 197348, Saint Petersburg, \\ Russia \\ ${ }^{3}$ Moscow State University of Civil Engineering, 26, Yaroslavskoye shosse, 129337, Moscow, Russia
}

\begin{abstract}
A new indicator for monitoring the level of labor protection at construction sites in the agricultural sector is proposed - the construction safety index with consideration of risk, which combines the Elmery system and the Fine-Kinney method. This method shows a complete picture of ensuring the level of labor protection at the construction site, taking into account emerging risk situations in the dynamics of construction. The universality of this approach allows each enterprise, depending on its technological features, to determine the list of hazards that it is going to control, which will allow predicting the development of negative scenarios, as well as planning the amount of money to ensure the proper level of labor protection.
\end{abstract}

\section{Introduction}

According to statistics, injuries are decreasing from year to year, but if we consider the individual sectors of the economy that pose the greatest danger, then the leaders remain: construction $-21 \%$, manufacturing-17\%, agro-industrial complex $-13 \%$, transport- $12 \%$, mining- $8 \%$ of the total number of deaths in labor production in 2018 [1-3]. Among the reasons for such high injuries are the human factor, unsatisfactory working conditions and lack of safety systems, as well as the level of labor protection.

Since the construction industry is one of the most traumatic, modern and effective methods based on a risk-based approach in the system of assessment and management of risks in labor protection are necessary. Many domestic and foreign authors [4] have considered the existing methods of assessing working conditions and the impact of risk situations on the life and health of an employee, but some elements of monitoring working conditions and production safety have not yet been sufficiently developed.

As practice shows, the system of occupational safety management and assessment of the impact of risk situations arising in the dynamics of construction production requires a comprehensive approach that would contribute to compliance with labor protection requirements in any production.

* Corresponding author: p198320@yandex.ru 
Using the Fine-Kinney method is one of the most common ways to assess risks. Analyzing the works of the authors [5-7], we can say that the use of the Fine-Kinney method solves the problems in the decision-making system when evaluating emerging hazards by pairwise comparison. Namely, using the MULTIMOORA method, etc. as well as ranking fuzzy numbers, you can determine the order of risk, as well as the priority response to reduce it.

The articles [8,9] consider the process of applying the Fine-Kinney method and its adaptation to certain production processes. In particular, the article [8] proposes to adapt this method for assessing the risk of deliveries in a transport company, which allowed us to rank the risks that most affect the security of supplies, and develop measures to reduce them. As a result, the developed system for assessing the safety of deliveries allows you to reduce operating costs, delivery times and costs, as well as reduce insurance premiums.

In another article [9], we consider the Fine-Kinney method with a structured technique for making complex decisions based on personal data for determining risks when using lifting equipment in construction production. As a result, the author proposed integrating the Fine-Kinney method with the ANR decision-making system, and the developed system was applied to lifting vehicles. Thus, it was possible to differentiate risks and determine priorities for responding to the identified risks.

Today, modern research is focused on the possibility of using new integrated approaches to ensure the safety of construction production and reduce industrial injuries, based on the integration of several systems. Integrated systems for assessing the safety of construction production have a high potential in the field of professional risk management and are developing the concept of acceptable risk and risk-based approach. The concept of acceptable risk itself seeks to achieve a level of risk that society can accept, and allows the principle of «anticipate and prevent».

\section{Materials and methods}

Today, a risk-based approach occupies an important place in the occupational health and safety management system, allowing you to pre-warn the development of negative events that would contribute to the injury of working personnel. Unfortunately, there is no single legally approved practice-oriented methodology for quantitative assessment of professional risks, but there is a wide variety of risk-oriented approaches to their assessment [10-12]. All this leads to difficulties in understanding the risk-based approach, and the tasks of risk management at the enterprise are already acute today. In connection with the above, a difficult task for a specialist in occupational safety at the enterprise becomes the choice of the most appropriate method of risk assessment.

To assess the objectivity of the choice of a particular risk assessment method, it is necessary to adapt the chosen method to the realities of production processes, i.e. it is necessary to develop a tool that would allow you to assess the situation at the inspected objects according to the set production tasks. The result of the check must be expressed in a final figure that can be compared with the reference indicator.

The construction industry is quite complex due to the dynamic nature of the work, and most of the presented methods for risk assessment are focused on the static nature of production processes. Among the many methods and approaches for monitoring the situation on the construction site for the level of labor protection, the simplest and most understandable is the Elmery system, based on the observation method and developed by the Institute of occupational health in Finland. The system uses a security index (Elmery index) or TR-barometer for risk assessment [13,14].

TR-barometer assumes an assessment of 6 factors that represent the main group of risks in the tested area: 
1. Production processes in which the use of personal protective equipment by employees (hereinafter referred to as PPE) is evaluated, as well as the compliance of work performance with regulatory documents is registered.

2. Scaffolding, bridges, trestles and ladders - assesses the serviceability of these structures in terms of their technical condition and application in the production process.

3. Labor Safety when working with machines and devices-all hand tools (pneumatic, power tools) are evaluated. The mechanisms involved in the production process are evaluated.

4. Means of protection from falls from a height-the presence employees from falling, as well as elements of the fence at height is assessed.

5. Electrical networks and lighting-all equipment connected with electricity is evaluated, as well as the serviceability of the electrical part of the power tool. The workplace is checked for compliance with illumination.

6. Order and cleanliness in the workplace-check the clutter of workplaces, the presence of containers for garbage and the timeliness of their removal.

The assessment is made by the method of observation of the inspector who is located directly on the evaluated site. The results of observations of the selected workplace are entered in the questionnaire on the principle of "good" / "bad". If it is not possible to evaluate any section, then just put "0".

The quantitative assessment of such verification is the security index "SI". This index is expressed as a percentage from 0 to $100 \%$ and is calculated as the ratio of "positive" ratings to the sum of "positive" and "negative" ratings multiplied by $100 \%$.

$$
\mathrm{SI}=\frac{\text { positive }}{\text { positive }+ \text { negative }} \times 100 \%
$$

In this case, the calculation is performed for each of the 6 factors and then displays the total for the checked area. This approach can be attributed to a risk-based approach in the labor protection system.

Analyzing this system, we can highlight the following advantages: ease of use and calculation of the index, applicability for monitoring labor protection in both small and large enterprises.

Disadvantages of the system:

- the assessment of the overall situation at the object being checked is carried out locally, which in turn can not show an objective picture at the site being checked;

- insufficient information content of the final coefficient;

- the inability to determine which factor has become critical for a particular workplace;

- the lack of boundary values indicating the level of risk tolerance.

To solve the latter drawback, an approach is proposed [15], based on ranking the influence of dangerous and harmful production factors, depending on the type of construction and installation work with reference to classes of working conditions.

With the transition to a risk-based approach and adoption by the state of regulations in this area, namely the Federal law No. 294 dated 26.12.2008 "On protection of rights of legal entities and individual entrepreneurs when exercising state control (supervision) and municipal control" and the Federal law No. 806 from 17.08.2016 "On the application of a risk-based approach in the organization of separate types of state control (supervision) and amendments to some acts of the Government of the Russian Federation" it is necessary to look for such methods which would allow to evaluate the risk more thoroughly.

One of these methods is the American Fine-Kinney method [14,16-18]. The main principle of this method is to evaluate individual risks based on the product of three characteristics: probabilities, impact and consequences, determined by an expert in accordance with table 1 . 
Table 1. $\mathrm{R}=$ Probability $\mathrm{x}$ Impact $\mathrm{x}$ Consequences.

\begin{tabular}{|c|l|c|l|c|l|}
\hline Points & \multicolumn{1}{|c|}{ Probability } & Points & \multicolumn{1}{|c|}{ Impact } & Points & \multicolumn{1}{|c|}{ Consequences } \\
\hline 10 & $\begin{array}{l}\text { Most likely, it will } \\
\text { happen }\end{array}$ & 10 & Constantly & 100 & $\begin{array}{l}\text { Emergency situation, } \\
\text { many victims }\end{array}$ \\
\hline 6 & Very probable & 6 & Daily during the working day & 40 & $\begin{array}{l}\text { Destruction, there are } \\
\text { victims }\end{array}$ \\
\hline 3 & $\begin{array}{l}\text { Uncharacteristic, but } \\
\text { possible }\end{array}$ & 3 & From time to time (weekly) & 15 & $\begin{array}{l}\text { Serious } \\
\text { consequences, there } \\
\text { is a fatal accident }\end{array}$ \\
\hline 1 & Unlikely & 2 & Sometimes (monthly) & 7 & $\begin{array}{l}\text { Disability, severe } \\
\text { injury }\end{array}$ \\
\hline 0.5 & It is hardly possible & 1 & Rarely (annually) & 3 & $\begin{array}{l}\text { Cases of temporary } \\
\text { disability }\end{array}$ \\
\hline 0.2 & Almost impossible & 0.5 & Very rarely & 1 & $\begin{array}{l}\text { Minor injury, first aid } \\
\text { provided }\end{array}$ \\
\hline 0.1 & Virtually impossible & \multicolumn{2}{l}{} & \multicolumn{2}{l}{} \\
\cline { 2 - 5 }
\end{tabular}

In each assessed case, it is determined how the detected violation of labor protection can contribute to injury or occupational disease. The final rating is the occupational risk index, which values range from 0 to 10,000 conventional units. At the same time, the urgency of preventive measures and the possibility of reducing or eliminating the increased professional risk index is based on the ranking of risk levels (table 2).

Table 2. Rating scale of professional risk parameters.

\begin{tabular}{|l|l|l|}
\hline \multicolumn{1}{|c|}{ Points } & \multicolumn{1}{c|}{ Risk } & \multicolumn{1}{c|}{ Preventive maintenance } \\
\hline$>320$ & Very high & Immediate termination of operations \\
\hline $160-320$ & Tall & Immediate improvement is needed \\
\hline $70-160$ & Significant & Improvement is needed \\
\hline $20-70$ & Possible & You need to pay attention \\
\hline$<20$ & Small & Subject to research \\
\hline
\end{tabular}

Depending on the results obtained, priorities are set for which preventive measures are needed to reduce risk situations that could affect the health of employees. Evaluating the advantages and disadvantages of this system, we note that one of the main drawbacks is the subjectivity in conducting the probability assessment, which in turn requires the involvement of competent specialists in this field with extensive experience and knowledge, as well as the lack of a standardized questionnaire that could be used to check the relevant elements of the production environment in advance.

The advantages include ease of calculation; the ability to map hazards in the workplace and graphically display their risk levels; flexible configuration for any type of production and any size of the enterprise.

Recently, the Fine-Kinney method has undergone minor changes compared to the original source $[16,17]$, which indicates its relevance when applied to risk assessment.

\section{Results and discussion}

The above methods of monitoring the level of labor protection work well separately, but as a result, we get two indicators: the safety index for the Elmery system and the risk as a product of three components. It is not easy to use these indicators for making organizational decisions and taking measures to ensure safe working conditions on the construction site. In 
particular, if the safety index shows increased percentages, which is good, then the risk, showing large values, already signals a dangerous state.

At the same time, it is unclear: what kind of dangerous and harmful production factor caused a decrease in safety on the construction site?

To improve understanding of the overall situation on the construction site, it is proposed to introduce a new integral indicator that reflects the impact of not only dangerous and harmful production factors, but also risk situations that may arise under the influence of certain dangerous and harmful production factors.

Using the Fine-Kinney system, we will determine the risk factors with a critical degree of danger that would maximally reflect the existing processes occurring on the construction site and correlate them with six control factors, according to the Elmery system, using the following formula:

$$
\text { Isr }=\mid\left(\frac{N \text { positive }}{N_{\text {negative }}+N \text { positive }}-\text { Rsum } / \text { Rmax }\right) \mid * 100 \%
$$

where: Isr-construction safety index taking into account the identified risk;

N_positive - the number of positive ratings of compliance with the rules labor protection at the object of control;

$\mathrm{N}_{\text {_ }}$ negative-the number of detected violations-negative assessments of compliance with labor protection rules at the control object;

Rsum-the sum of points for identified risks calculated using the Fine-Kinney method;

Rmax - the maximum score based on the Fine-Kinney method.

Thus, the construction safety index (Isr) was obtained, taking into account the risk component; at the same time, it was possible to identify the real impact of risk situations occurring in the dynamics of the construction process on the overall safety index.

Considered example. There is a control area where production processes take place. As a result of monitoring and calculation using the Elmery system, 15 positive and 4 negative marks were obtained. According to formula (1), the security index will be:

$$
(15 /(4+15)) * 100 \%=78.9 \% \text {. }
$$

Knowing the boundary values of the influence of dangerous and harmful factors $[15,19,20]$, we get the level of safety at this site - "optimal", working conditions are also "optimal". The following risk situations were identified during the monitoring process:

1. The worker in the front cradle does not use fall protection systems. We will calculate the risk using the Fine-Kinney system according to the formula (2): the probability of injury to the employee is 6 points, the impact is 6 points, the consequences are 15 points, and the risk is obtained:

$$
\mathrm{R}=6 \times 6 \times 15=540 \text { points. }
$$

According to table 2, we get that the risk is "high and requires immediate termination of activity".

2. The situation in the form of a defect in load-handling devices has been Identified. Use of defective lifting devices, such as slings, traverses, grabs, etc. at any moment, a break may occur, which will lead to severe consequences for both the slingers themselves and the workers who are on the working horizon, where the cargo was delivered.

Let's assume that an accident can occur when using such defective devices, then the probability is 10 points, the impact is during working time, i.e., the risk of an accident is 10 points. 6 points, but the consequences can be fatal, up to a fatal outcome, i.e. 15 points. According to the formula (2): 


$$
\mathrm{R}=10 \times 6 \times 15=900 \text { points. }
$$

According to table 2, we get that the risk is "high and requires immediate termination of activity".

Summing up the identified risks in the control area, we get the identified risk:

$$
\text { Rsum }=540+900=1440
$$

Since according to the Fine-Kinney method, the maximum Rmax $=10 \times 10 \times 100=$ 10,000 points, we calculate the «weight» of the identified risks as a quotient of the identified risk to the maximum risk: $1440 / 10000=0.144$.

Using the formula (3), we will find the construction safety index, taking into account the risk component:

$$
\mathrm{Isr}=|(0.789-0.144)| * 100 \%=64,5 \%
$$

Another example of calculation: the sum of the identified risks Rsum $=9000$ points, "weight" of identified risks $=9000 / 10000=0.9$,

$$
\mathrm{Isr}=|(0,87-0,9)| * 100 \%=3 \%
$$

Thus, a number is obtained that takes into account both the influence of dangerous and harmful production factors, and the risks arising from their influence.

\section{Conclusions}

The presented approach to assessing the level of labor protection based on an integral indicator allows us to identify the processes and factors that most affect labor safety. This makes it possible to effectively adjust the choice of protective measures on the construction site.

The universality of this approach allows each enterprise, depending on its technological features, to determine the list of hazards that it is going to control. In turn, this will allow you to predict the development of negative scenarios, as well as calculate the amount of money to ensure the proper level of labor protection.

The proposed approach can work with any number of types of identified hazards and on any control area.

\section{References}

1. The Ministry of labor announced statistics of occupational accidents in Russia, https://coko1.ru/news/protection-news/mintrud-ozvuchil-statistiku-proizvodstvennogotravmatizma-v-rossii/

2. Working Conditions, https://www.gks.ru/working_conditions?print=1

3. Results of the year in the field of labor protection, https://rosmintrud.ru/labour/safety/294

4. V.V. Sharmanov, Monitoring and evaluation of the level of labor protection in construction production with the involvement of a complex of BIM-technology tools (Volgograd, 2020)

5. W. Wang, Computers \& Industrial Engineering 125, 111-123 (2018)

6. A. Kokangül, Safety Science 91, 24-32 (2017)

7. M. Gul, Journal of Loss Prevention in the Process Industries 53, 3-16 (2018) 
8. A. Zahira Gabriela Cruz Netro, 7th International Conference on Safety and Security Engineering 174, 43-55 (2017)

9. F. Yilmaz, Advances in Science and Technology Research Journal 13(3), 152-161 (2019)

10. Risk management - Risk assessment techniques: ISO/ IEC 31010 : 2009 (IEC, Geneva, 2009)

11. Russian Federation Standards: GOST 12.0.004-2015 (Standardinform, Moscow, 2016)

12. Russian Standards: GOST $\quad R \quad$ 58771-2019, http://rdocs3.kodeks.ru/document/1200170253

13. H. Laitinen, Manual for monitoring working conditions in the workplace in industry. Elmery system (Institute of professional health of Finland, Helsinki, 2000)

14. B.V. Sevastyanov, Safety in the technosphere 1, 13-18 (2008)

15. V.V. Sharmanov, Proceedings of the 14th International scientific and practical conference on ecology and security, 181-187 (2016)

16. Yu.A. Bulavka, Safety of life 7, 9-15 (2013)

17. Yu.A. Bulavka, Bulletin of Polotsk state University. Ser. B, Industry, Applied Sciences 3, 156-163 (2013)

18. I.S. Stepanov, Gorny information and analytical Bulletin (scientific and technical journal) 3(11), 12 (2016)

19. V.V. Sharmanov, Construction of unique buildings and structures 12(63) (2017)

20. V.V. Sharmanov, Academic Bulletin of Uralniiproekt RAASN 3(34), 72-79 (2017) 